\title{
Euploid chicken embryos from eggs containing one, two or several yolks*
}

\author{
K.-H. Lee†, N. S. Fechheimer† $\ddagger \S$ and H. Abplanalp $q$ \\ Departments of $\dagger$ Molecular Genetics, $\$$ Dairy Science and $\S$ Poultry Science, The Ohio State \\ University, Columbus, Ohio 43210, USA; and Department of Avian Science, University of \\ California, Davis, CA 95616, USA
}

\begin{abstract}
Summary. A high incidence of haploid/diploid chimerism in chick embryos from strains of chickens selected for large size was postulated to be caused by the propensity of such hens to ovulate erratically. To test the hypothesis karyological analysis was made of embryos in eggs containing 1 or $>1$ yolk. The eggs were from a line selected for multiple ovulation for 20 generations. Double and multiple-yolk eggs are a manifestation of an irregular ovulatory pattern. Ova in multiple yolk eggs were significantly less fertile and significantly fewer embryos survived to $18 \mathrm{~h}$ of incubation than single ovulated ova.

In the sample of 342 embryos analysed, only 2 forms of heteroploidy occurred in frequencies of $>1 \cdot 2 \%: 2 n / 4 n$ mosaicism $(5 \cdot 8 \%)$ and $3 n(5 \cdot 0 \%)$. Only triploidy occurred significantly more frequently in eggs containing $>1$ yolk $(7.0 \%)$ than in single yolk eggs (none). The overwhelming majority of $3 \mathrm{n}$ embryos had a digynic origin (i.e. from ova with 2 maternal pronuclei), as inferred from the sex chromosome complement. Erratic ovulation therefore resulted in suppression of second polar body extrusion leading to digynic triploidy. Multiple yolks had no effect on dispermy, the primary cause of $1 \mathrm{n} / 2 \mathrm{n}$ chimaeric embryos, in single-yolked chicken eggs.
\end{abstract}

Keywords: chick embryo; multiple ovulation; heteroploidy; fertility

\section{Introduction}

The reproductive performance of domestic animals is limited partly by the occurrence of early embryonic death. Indications from extensive work with human abortuses, and fertilized eggs of mice and other laboratory mammals as well as more limited studies in cattle, sheep, and pigs indicate that a variable but important proportion of early embryos is afflicted with abnormal chromosome complements. Errors during the processes of germ cell proliferation, gametogenesis, fertilization, and early cleavage division of the fertilized egg are all sources of one or more types of chromosomal abnormalities resulting in subsequent maldevelopment or death of the embryo. It is necessary to identify the factors of importance in causing the errors.

The domestic chicken is particularly useful for studies of karyotypic anomalies of embryos (Fechheimer, 1990). In several lines of chicken and one of Japanese quail selected for rapid growth the frequency of chimaeric embryos bearing both haploid and diploid cells $(1 n / 2 n)$ was 3-5 times greater than in control lines (Miller et al., 1971; Reddy \& Siegel, 1977; Wolowodiuk et al., 1985). Difference, between lines in frequency of $1 \mathrm{n} / 2 \mathrm{n}$ chimaeras were also noted by Bloom (1974) and Snyder et al. (1975). The haploid cell component of such embryos is invariably derived from a supernumerary spermatozoon that enters the egg, does not engage in syngamy but instead proliferates independently by mitosis (Fechheimer \& Jaap, 1978, 1980). It was postulated that the high

*Reprint requests: N. S. Fechheimer, Dairy Science Department, 2027 Coffey Rd, Columbus, Ohio 43210, USA. 
frequency of $1 \mathrm{n} / 2 \mathrm{n}$ embryos in lines of large birds was associated with the irregular ovulatory cycle characteristic of large chickens (Jaap \& Muir, 1968). Irregular ovulation yields ova that are immature or senescent, perhaps rendering them more susceptible to polyspermy. To test this hypothesis the incidence of chromosomal abnormalities in double-yolked eggs is compared, in this study, to that of single-yolked eggs layed by the same hens. It is assumed that one or both of the yolks contained in double-yolked eggs were ovulated at a time other than optimum for meiotic maturation.

\section{Materials and Methods}

Source of fertile eggs. The eggs were from a line of Leghorn chickens selected for 20 generations for production of double yolked-eggs (DY line) to an age of 40 weeks. Currently more than $30 \%$ of eggs contain 2 yolks and an additional proportion contain 3, 4, or even 5 yolks. Details of the development and performance of this closed population, and comparisons with a control line selected for egg number have been reported previously (Abplanalp $e t$ al., 1977; Abplanalp, 1984). Hens were artificially inseminated weekly with semen from males of the same line. Eggs were collected daily and identified as to date of oviposition and the hen from which they came. After storage for a maximum of 6 days they were shipped by air freight. Six shipments of eggs were made from Davis, California, where the chickens were housed, to Ohio where the laboratory work was done. Two shipments of eggs were from I-year-old hens of generation 19 of selection, and 4 shipments were from generation 20, at the beginning of the hens' laying cycle.

Processing of eggs. When shipments of eggs were received they were stored at $10^{\circ} \mathrm{C}$ for a maximum of 7 days. Groups of 20 eggs were removed from storage and placed in an incubator at $39^{\circ} \mathrm{C}$ for $16 \mathrm{~h}$. Then each yolk was injected with $0.1 \mathrm{ml}$ of an aqueous colchicine solution containing $0.1 \mathrm{mg}$ colchicine to arrest mitotic cells at metaphase. Eggs were returned to the incubator for a further $2 \mathrm{~h}$ of incubation.

The eggs were then (i.e. after incubation for a total of $18 \mathrm{~h}$ ) opened and the contents emptied into a Petri dish. When eggs were opened the number of yolks and position of each within the egg were recorded. Blastoderms were carefully removed from each yolk with a scalpel and dissociated by aspiration with a Pasteur pipette in small $(3 \mathrm{ml})$ centrifuge tubes containing $2 \mathrm{ml}$ TC 199 medium. Hypotonic treatment, fixation, and making and staining of slides were done according to the procedure of Miller et al. (1971).

Each slide containing the material of a single blastoderm was scanned under low power of a standard light microscope. If no cells were seen the blastoderm was considered to have been infertile. If cells were seen but none was at metaphase, the embryo was scored as dead. When slides contained cells at metaphase the embryo was scored as living and a minimum of 5 cells at metaphase were scrutinized under an oil immersion objective. Karyotypic analysis involved identification of the 8 largest pairs of autosomes and the sex chromosomes, $\mathrm{Z}$ and $\mathrm{W}$. Because 30 pairs of microchromosomes are too small to be identified, or even to be counted accurately, they were disregarded.

Analysis of data. Heterogeneity $\chi^{2}$ tests were made to test the significance of differences between eggs containing single yolks, 2 yolks, or $>2$ yolks. Data pertaining to fertility, embryonic viability, sex proportion of embryos, and proportion of embryos bearing chromosomal abnormalities were analysed.

\section{Results}

\section{Fertility and embryonic viability}

Of a total of 417 eggs containing 709 yolks, 163 contained a single yolk, 218 contained 2 yolks, and 36 contained $>2$ yolks ( 34 with 3 and 2 with 4 yolks). Owing to the small numbers in the last two categories they were combined and referred to hereafter as multiple-yolked eggs. During processing of eggs 30 yolks were broken and so their blastoderms could not be recovered, leaving 679 that could be scored for fertility and embryonic viability. Differences among the 3 types of eggs for both fertility and embryonic viability were significant $(P<0.0001)$. Single-yolked eggs were most fertile and multiple-yolked eggs were least fertile. Embryonic viability was greatest in single-yolked eggs and lowest in multiple-yolked ones (Table 1).

\section{Sex proportion of embryos}

Genetic sex of 293 diploid embryos was assigned according to their sex chromosome complement, ZZ being male and ZW female. No sex chromosome aneuploidy was obseryed The $_{\mathrm{D}}$ sex $_{14 \mathrm{AM}}$ 
Table 1. Number and (percentage) of fertile ova and live embryos in single-, double- and multipleyolk eggs

\begin{tabular}{lcrr}
\hline $\begin{array}{l}\text { No. of } \\
\text { yolks/egg }\end{array}$ & $\begin{array}{c}\text { Total no. } \\
\text { of yolks } \\
\text { processed }\end{array}$ & $\begin{array}{c}\text { Fertile } \\
\text { blastoderms* }\end{array}$ & \multicolumn{1}{c}{$\begin{array}{c}\text { Live } \\
\text { embryos* }\end{array}$} \\
\hline 1 & 155 & $124(80 \cdot 0)$ & $99(79 \cdot 8)$ \\
2 & 417 & $288(69 \cdot 1)$ & $215(74 \cdot 7)$ \\
3 or 4 & 107 & $57(53 \cdot 3)$ & $28(49 \cdot 1)$ \\
Total & 679 & $469(69 \cdot 1)$ & $342(72 \cdot 9)$ \\
\hline
\end{tabular}

${ }^{*} P<0.0001$.

proportion ( \pm s.e.) of the three types of eggs, calculated as percentage of males, was $53 \cdot 8 \pm 5 \cdot 2 \%$, $44.4 \pm 3.7 \%$, and $30.4 \pm 9 \cdot 6 \%$ for single-, double-, and multiple-yolked eggs respectively. The differences were not significant $(P>0 \cdot 1)$ and so the data were pooled to yield an overall sex proportion of $46 \cdot 1 \pm 2 \cdot 9 \%$, which is not significantly different from the expected $50 \%(P>0 \cdot 1)$.

\section{Frequency of heteroploidy}

The chromosomal complements of 342 embryos from which $\geq 5$ cells were karyotyped are shown in Table 2 . The incidence of embryos with chromosomal abnormalities was $14.3 \%$ comprising two prevalent types, diploid/tetraploid mosaics (5.3\%) and triploidy $(5 \cdot 0 \%)$, and several other types which occurred with frequency lower than $1 \cdot 2 \%$. Only $3(0 \cdot 9 \%)$ haploid and haploid/diploid chimaeric embryos were observed. Triploid embryos were significantly more frequent in eggs containing two or more yolks $(7 \cdot 0 \%)$ than in those with a single yolk in which none occurred $(P<0.001)$. For all other types of chromosomal abnormalities the differences in frequency among the 3 types of eggs were not significant. Three unusual types of chimaerism were observed: a single $2 n / 6 n$ in a single-yolk egg, and a $2 n / 5 n$ and $3 n / 5 n$ in double-yolk eggs.

The sex chromosome complements of polyploid and euploid chimaeric embryos are useful as markers to infer the site of origin of some forms of heteroploidy. The 17 pure triploids had sex chromosome complements of ZZZ (4), ZZW (3), and ZWW (10). Of the $2 \mathrm{n} / 4 \mathrm{n}$ mosaic embryos, 4 were $Z Z / Z Z Z Z$ and 14 were $Z W / Z Z W W$. The $2 n / 6 n, 2 n / 5 n$, and $3 n / 5 n$ embryos had sex chromosome complements of ZZ/ZZZZZZ, ZZ/ZZZWW and ZZW/ZZZWW respectively.

\section{Discussion}

The present experiment, in which embryos from singly ovulated and multiply ovulated eggs from the same hens were examined, was done to test the hypothesis that mistimed ovulation increases the occurrence of dispermy. In chickens dispermy yields $1 \mathrm{n} / 2 \mathrm{n}$ chimaeric embryos (Fechheimer \& Jaap, 1978,1980 ). The finding that $1 \mathrm{n} / 2 \mathrm{n}$ embryos were no more frequent in double- or multiple-yolked eggs than in single-yolked ones, and in fact was notably low $(0.9 \%)$ in all three categories of eggs, indicates that irregular ovulatory cycles are not causally related to production of $1 \mathrm{n} / 2 \mathrm{n}$ embryos which must be a result of some other anomaly of large chickens. Perhaps ova from hens with a propensity to produce $\ln / 2 \mathrm{n}$ embryos contain a factor that induces mitosis of spermatozoa.

The single tetraploid embryo and additional 19 diploid/tetraploid $(2 n / 4 n)$ embryos were recovered from the 3 types of eggs in frequencies that were not significantly different. As in all previous studies of chicken embryos the tetraploid component was the exact double of the diploid component, i.e. when the diploid component had gonosomes $\mathrm{ZZ}$, the tetraploid component was $\mathrm{ZZZZ}$, and if the diploid component was ZW, the tetraploid component was ZZWW. It has been 
Table 2. Number and (percentage) of diploid and heteroploid embryos in single-, double- and multiple-yolk eggs

\begin{tabular}{lcccc}
\hline $\begin{array}{l}\text { Chromosome } \\
\text { complements } \\
\text { of embryos }\end{array}$ & \multicolumn{3}{c}{ No. of yolks/egg } & \\
\cline { 2 - 4 } & 1 & 2 & 3 or 4 & Totals \\
\hline Diploid (2n) & 91 & 179 & 23 & 293 \\
& $(91 \cdot 9)$ & $(83 \cdot 3)$ & $(82 \cdot 1)$ & $(85 \cdot 7)$ \\
Haploid (1n) and & 0 & 2 & 1 & 3 \\
$\quad$ In/2n chimaeras & & $(0 \cdot 9)$ & $(3 \cdot 6)$ & $(0 \cdot 9)$ \\
Triploid (3n)* & 0 & 15 & 2 & 17 \\
& & $(7 \cdot 0)$ & $(7 \cdot 1)$ & $(5 \cdot 0)$ \\
Tetraploid (4n) and & 6 & 13 & 1 & 20 \\
$\quad$ 2n/4n mosaics & $(6 \cdot 1)$ & $(6 \cdot 0)$ & $(3 \cdot 6)$ & $(5 \cdot 8)$ \\
$\begin{array}{l}\text { Other euploid } \\
\text { chimaeras 2n/6n; }\end{array}$ & 1 & 2 & 0 & 3 \\
2n/5n; 3n/5n & $(1 \cdot 0)$ & $(0 \cdot 9)$ & & $(0 \cdot 9)$ \\
Aneuploid and & 1 & 2 & 1 & 4 \\
$\quad$ aneuploid mosaic & $(1 \cdot 0)$ & $(0 \cdot 9)$ & $(3 \cdot 6)$ & $(1 \cdot 2)$ \\
Structural & 0 & 2 & 0 & 2 \\
$\quad$ aberration & & $(0 \cdot 9)$ & & $(0 \cdot 6)$ \\
\hline Totals & 99 & 215 & 28 & 342 \\
\hline
\end{tabular}

*Difference among egg types, $P<0-001$.

concluded that such mosaic embryos are derived from normally fertilized eggs when mitotic division fails during early cleavage (Fechheimer, 1981). Such embryos are not randomly distributed among the progeny of all parents but cluster within the eggs produced by single sires or dams (Miller et al., 1976). In the present study 5 of the 56 dams from which eggs were collected each produced two $2 \mathrm{n} / 4 \mathrm{n}$ embryos.

The 17 triploid ( $3 n$ ) embryos were recovered only from double and multiple yolk eggs, in which their frequency was $7.0 \%$. None was recovered from single yolk eggs. Analysis of the gonosome complements indicates that most were of digynic origin resulting from failure of the second meiotic division (MII) of oocytes. Failure of MII of oogenesis should yield ootids with WW and ZZ in equal numbers. Fertilization with normal spermatozoa then results in 3 n embryos with sex chromosomes ZWW and ZZZ. Other mechanisms resulting in triploidy, such as first meiotic division (MI) failure of oogenesis and dispermy, yield $Z Z Z$ and ZZW embryos (Mong et al., 1974). In this study 10 of the 17 triploid embryos were ZWW, 4 were $Z Z Z$ and 3 were $Z Z W$. Therefore, between 59 and $82 \%$ originated from MII failure during oogenesis. The remainder probably arose as a result of failure of MI of oogenesis because dispermy in chickens usually results in $1 \mathrm{n} / 2 \mathrm{n}$ embryos, not diandric triploidy (Fechheimer \& Jaap, 1978, 1980; Fechheimer, 1981).

Multiple ovulation in the chicken therefore increases significantly the incidence of meiotic failure, particularly failure of MII. As in mammals MII occurs shortly after fertilization, and is probably initiated by it. Eggs not in the optimum physiological state perhaps cannot undergo MII when stimulated to do so by sperm entry, because all components necessary for its occurrence are not mobilized or organized in the case of prematurely ovulated eggs, or because some of the necessary components have become dispersed, disorganized, or degraded in the case of senescent eggs.

Further evidence supports the importance for fertilization of eggs within a limited span to time for subsequent events to occur normally. Bloom (1974) and Mong et al. (1974) noted that triploid chick embryos were more frequent early in the laying cycle of young hens, when ovulation is occurring irregularly. In both studies most of the $3 \mathrm{n}$ embryos resulted from suppression of MII of the oocyte. 
In accord with previous studies (Jeffrey et al., 1953; Fechheimer \& Jaffe, 1966) both fertility and viability of double-yolk eggs were lower than in those with a single yolk. In this study all eggs were opened and embryos were processed for detailed examination at $18 \mathrm{~h}$ of incubation. It was therefore possible to discriminate between infertile blastoderms and those that were fertile but died very early in development. The proportion surviving to $18 \mathrm{~h}$ of incubation was only slightly reduced in double-yolked eggs but was significantly lower $(P<0.001)$ in multiple-yolked eggs (Table 1). Both the lower fertility and embryonic viability of double- and multiple-yolked eggs must be attributable to properties of the egg because the full fertility of available spermatozoa is indicated by the observations of single-yolked eggs fertilized by spermatozoa of the same inseminates. To be encased in a single shell, 2 or more yolks must be ovulated within a time span of $1 \mathrm{~h}$. It is unlikely that two or more yolks spontaneously ovulated in such a short interval are at the same state of maturation. It is probable therefore that the reduced fertility and embryonic viability of blastoderms on multiply ovulated yolks both result from the mistimed ovulation of one or both of the yolks contained in double-yolked eggs. From this study it is not possible to decide whether the detrimental effects are more pronounced in immature or senescent blastoderms. There were no significant differences, however, in fertility or embryonic viability of yolks in the two ends (acute and rounded) of double-yolked eggs. The yolk in the acute end is the first one ovulated. It seems probable therefore that both premature and delayed ovulation have detrimental effects, but probably for different reasons.

Although the differences in sex proportion (\% male) of embryos in single-, double- and multiple-yolked eggs were not significant they are notably large and exhibit a trend. The proportion declined from $53.5 \%$ in single-yolked eggs to $44.4 \%$ in double-yolked ones, and to $30.4 \%$ in eggs with 3 or 4 yolks. Prior observations of large samples of embryos at the same stage of development, in numerous experiments, indicated that the normal sex proportion is very close to $50 \%$ (Fechheimer et al., 1970; Fechheimer \& Jaap, 1974; and further unpublished data). All spermatozoa carry a $\mathrm{Z}$ chromosome. A decrease in sex proportion might therefore indicate a preferential segregation of the $\mathrm{W}$ chromosome to the ovum at first meiotic division of the oocyte. Alternatively, a shift in the sex proportion such as was observed could have resulted from more frequent death of male embryos in multiple-yolked eggs before $18 \mathrm{~h}$ of incubation. Absence of embryos with sex chromosome aneuploidy indicates that non-disjunction of the sex bivalent at first meiotic division did not occur.

The primary finding of this work is that multiple ovulation increased the incidence of meiotic failure, particularly that of the second meiotic division. The incidence of haploid/diploid chimaeric embryos was not increased by multiple ovulation. Because such aberrant embryos result from mitotic proliferation of a supernumerary spermatozoon, a factor present in the cytoplasm of ova from some hens might promote sperm mitosis.

Salaries and research support partly provided by State and Federal funds appropriated to The Ohio Agricultural Research and Development Center, The Ohio State University. Journal article No. 249-89. Supported in part by a grant-in-aid from the Central Ohio Breeding Association.

\section{References}

Abplanalp, H. (1984) Selection for high numbers of multiple yolked eggs in White Leghorns. Ann. Agric. Fenn. 23, 211-215.

Abplanalp, H., Lowry, D.C. \& van Middelkoop, J.H. (1977) Selection for increased incidence of doubleyolked eggs in White Leghorn chickens. Br. Poult. Sci. 18, 585-595.

Bloom, S.E. (1974) The origins and phenotypic effects of chromosome abnormalities in avian embryos. Proc.
I5th World's Poultry Congr., pp. 316-320. McGregor and Warner, Washington, D.C.

Fechheimer, N.S. (1981) Origins of heteroploidy in chicken embryos. Poult. Sci. 60, 365-371.

Fechheimer, N.S. (1990) The domestic chicken (Gallus domesticus) as an organism for the study of chromosomal aberrations. In Farm Animals in Biomedical Research, pp. 43-54. Eds V. Pliska \& G. Stranzinger. P. Pareybatamburg Bioscientifica.com at 04/26/2023 09:32:14AM 
Fechheimer, N.S. \& Jaap, R.G. (1974) Sex proportion in early embryos of domestic fowl (Gallus domesticus). Genetics, Princeton 74 (Suppl.), 77, abstr.

Fechheimer, N.S. \& Jaap, R.G. (1978) The parental sources of heteroploidy in chick embryos determined with chromosomally marked gametes. J. Reprod. Fert. 52, 141-146.

Fechheimer, N.S. \& Jaap, R.G. (1980) Origins of euploid chimerism in embryos of Gallus domesticus. Genetica 52/53, 69-72.

Fechheimer, N.S. \& Jaffe, W.P. (1966) Fertility and embryo death in double-yolked eggs. J. Reprod. Fert. 12, 363-364.

Fechheimer, N.S., Lodge, J.R. \& Miller, R.C. (1970) Sex proportion of domestic chicken at 16 hours of incubation. J. Reprod. Fert. 23, 365-367.

Jaap, R.G. \& Muir, F.V. (1968) Erratic oviposition and egg defects in broiler-type pullets. Poult. Sci. 47, $417-423$

Jefirey, F.P., Fox, T.W. \& Smyth, J.R., Jr (1953) Observations on double yolked eggs from the domestic fowl. J. Hered. 44, 213-216.
Miller, R.C., Fechheimer, N.S. \& Jaap, R.C. (1971) Chromosome abnormalities in 16- to 18-hour chick embryos. Cytogenetics 10, 121-136.

Miller, R.C., Fechheimer, N.S. \& Jaap, R.G. (1976) Distribution of karyotype abnormalities in chick embryo sibships. Biol. Reprod. 14, 549-560.

Mong, S.F., Snyder, M.D., Fechheimer, N.S. \& Jaap, R.G. (1974) The origin of triploidy in chick (Gallus domesticus) embryos. Canad. J. Genet. Cytol. 16, 317-322.

Reddy, P.R.K. \& Siegel, P.B. (1977) Chromosomal abnormalities in chickens selected for high and low body weight. J. Hered. 68, 253-256.

Snyder, M.D., Fechheimer, N.S. \& Jaap, R.G. (1975) Incidence and origin of heteroploidy, especially haploidy, in chick embryos from intraline and interline matings. Cytogenet. Cell Genet. 14, 63-75.

Wolowodiuk, V.D., Fechheimer, N.S., Nestor, K.E. \& Bacon, W.L. (1985) Chromosome abnormalities in embryos from lines of Japanese quail divergently selected for body weight. Génét. Sél. Evol. 17, $183-190$.

Received 25 July 1989 